\title{
The Dipylon Mistress: Social and Economic Complexity, the Gendering of Craft Production, and Early Greek Ceramic Material Culture
}

\author{
SARAH C. MURRAY, IRUM CHORGHAY, AND JENNIFER \\ MACPHERSON
}

This article considers the role of changing contexts of production in the evolution of ceramic material culture in early Greece. Rather than focusing on the aesthetics of ceramics or reading political and social change from patterns in ceramic style and consumption, we consider Early Iron Age (EIA) ceramic style in its context of production. Isolating the idiosyncratic aspects of EIA material culture and evaluating them in dialogue with the ethnographic record, we argue that dynamics of change in EIA ceramic repertoires may be best explained as the result of evolving contexts of production after the Bronze Age collapse that resulted in women having an increased and prominent role in potting and painting vessels. Likewise, stylistic changes occurring in the late eighth and seventh centuries BCE may be related to a transition back to a more complex economic structure in which ceramic style was driven by profit-seeking male potters. ${ }^{1}$

\section{INTRODUCTION}

Analysis of Early Iron Age (EIA, ca. 1050-700 BCE) material culture has most often centered on issues of aesthetics and political and social history. On the one hand, scholars of Greek art have attempted to explain stylistic developments in EIA ceramic material culture as the result of changing ideologies, the presence of a collective spirit usually related to the notion of order, or the creative vision of individual named geniuses, such as the so-called Dipylon Master. ${ }^{2}$ On the other hand, historians and archaeologists studying early Greece have aimed to connect patterns in ceramic material culture with issues of sociopolitical development, for example, the role of mortuary

American Journal of Archaeology

Volume 124, Number 2

April 2020

Pages 215-44

DOI: 10.3764 /aja.124.2.0215

www.ajaonline.org

\footnotetext{
${ }^{1}$ We would like to thank Philip Sapirstein, Jeremy Rutter, Dimitri Nakassis, and Sylvian Fachard for helpful discussions and comments on earlier drafts of this paper; John Papadopoulos and two anonymous reviewers for the $A J A$ for constructive criticism during the review stage; and AJA Editor-in-Chief Jane B. Carter for superlative guidance and suggestions throughout the editorial process. Remaining flaws and errors are the responsibility of the authors.

${ }^{2}$ The ideas of Himmelmann-Wildschütz $(1962,10)$ and Kübler (1970, 3) about orderly, tectonic style reflect something along these lines. Formulations of the relationship between the desire to depict order and the clearly structured designs of Protogeometric and Geometric pottery decoration are common, e.g., Benson 1982, 542-43, 548. On the idea that the pottery represents the spirit of the age, see Desborough 1948, 261; Starr 1961,99103; Coldstream 1968, 1-2; Carter 1972, 36; Desborough 1972, 292; Johnston 1976, 58; Benson 1982, 548. On the Dipylon Master, see Ahlberg-Cornell 1992, 19; Coulié 2015.
} 